\title{
The Changes in the Semanteme of the Word “贵” and it's Educational Significance
}

\author{
Lihuang Liu \\ Jingdezhen Ceramic Institute, Jingdezhen, Jiangxi 333403, China
}

\begin{abstract}
Keywords: Chinese Character “贵”; Changes in the Semanteme; Educational Significance; Ways of Moral Cultivation
\end{abstract}

\begin{abstract}
In contrast to the usage in ancient Chinese, great changes have taken place in the present usage of the Chinese character “贵”, its part of speech and the scope of its meaning differing a lot. The analysis of its social attribute finds that these changes reflects the modern society's pursuit of equality on the one hand, and the loss of some value pursuits held dear by ancient Chinese people on the other. These value pursuits are of great educational significance to the moral cultivation of the present society. This thesis is to relocate the lost value pursuits reflected by the current meanings of the word, and explore an effective way to exert the educational function of these value pursuits.
\end{abstract}

\section{Introduction}

The character“贵” is used most frequently in ancient Chinese. Some ancient literature record the discussions of ancient philosophers and thinker about "Heweigui", some ancient literature record the concepts and behaviors of the ancient sages for the issue of wealth and rank, and some ancient literature show the people's love of things which symbolize wealth and rank. To apply the definition of culture (the floorboard of thoughts, concepts, behaviors, customs, habits and representatives of the specific social groups formed in a certain period), these discussions, concepts, behaviors and the adoration of certain things themselves constitute a beautiful sign line-the culture of wealth and rank of Chinese traditional culture. The development of the culture of wealth and rank has an important significance to solve the social problems such as credit-cracking, wealth without rank and official without rank. It will help to find the cultural root of the above social problems to compare the modern meaning of the character “贵” with the ancient meaning of the character “贵”. Digging up the educational values of the character “贵” is conductive to carry forward some noble spiritual pursuit in recent society.

\section{Change of Semantics and Problems Reflected by the Change}

Due to the change of the history culture, the modern semantic of the character “贵” is very different from the ancient semantic of the character “贵”. Although the character “贵” accepted partial meaning in the ancient Chinese, there are still some large changes not only in the aspect of the part of speech but also in the aspect of the denotative meaning.

Similarities of Semantics. When used as an adjective, there is a high overlapping degree between the modern meaning of the character “贵” and the ancient meaning of the character “贵”. It is the definition of the character “贵” in "Shuowen" that the prices of things are not cheap. There is a character “贝” in the character “贵” which is related to wealth. The original meaning of the character “贵” is high price compared with low price that is a common meaning of the character “贵” from ancient to modern times. For example, “Granaries are established in many places close to the frontier which are used to stockpile grains when the price of grain is low, and sell grains when the price of grain is high. These granaries are very benefit for the farmers, and which are called ever-normal granaries" in "Shihuo Zhi in Han Dynasty". It has the same meaning that vegetables are really expensive that are frequently said by people. The modern character “贵” has the same meaning with the ancient character “贵” when its meaning is valuable and important. The term “贵 
器” in ancient articles and the term “宝贵” in modern articles are two good examples. The character “贵” also has the meaning of having high social status when it is used as an adjective. There are two good examples "The position in society is may be compared with things, as the identity hierarchy may be compared with appliance" in "Guangya" and "honoured guest" in modern Chinese. The character “贵” also can be used to form a title for the things related to the other side as a respect, and that is a common usage from ancient to modern times. For example, “贵上”, “贵公司” etc.

The modern character “贵” has the same usage with the ancient character “贵” when it is used for politeness. There are two good examples “有何贵干” and “贵庚”. When the character “贵” is used to refer to place name and surname as a noun, the modern character “贵” has the same usage with the ancient character “贵”. There are three good examples “贵州”, “云贵高原” and “汉有庐 江太守贵迁”. The character “贵” also can be used to refer to a person with prominent position when it is used as a noun. For example, the term “贵门” (bigwigs) and the term “贵阶” (the officials of Tang Dynasty are divided into nine grades, in which, the officials above the fifth grade are called “贵阶” ) in the ancient Chinese, in addition, the term “权贵” in modern Chinese is a good example.

Differences of Semantics. The changes of semantics of the character “贵” are great when it is used as a verb, and there are partial changes when it is used as a noun. In modern Chinese, the character “贵” is rarely used as a verb, and the usage as a noun in ancient Chinese is slowly being lost. The character “贵” has the meaning of raising prices in ancient Chinese when it is used as a verb. For example, "The price of grains must be raised if you want people to carry out farming in peace" in "Lun Guisushu”. In addition, the character “贵” also has the meaning of advocating or paying attention to somethings, for example, "Alienate the little man and away from the attractive woman, disdain money and goods, but pay more attention to moral integrity" in " $\mathrm{Li}$, Zhongyong". Some terms of ancient Chinese embody the meaning of the character “贵” such as “贵贵”, “贵爱” and “贵农贱商”. But in modern Chinese, the character “贵” has slowly been losing the two kinds of usages as a verb.

The character “贵” has the meaning of hard core when it is used as a noun. From the grapheme, the character “贵” includes three parts “中”, “一” and “贝” which is the bottom (refers to strategic value), the combination of the three parts refers to the key point and support point with strategic value. Later, the character “贵” is also used to refer to the critical persons who are responsible for defending their countries. For example, in Western Han Dynasty, the character “贵” was used to refer to all the strategic locations of the network of dynastic rule and the important officials responsible to defend these important locations. These meanings of the character “贵” are out of use in modern Chinese.

In a word, the semantic scope of the character “贵” is becoming narrower and narrower in modern Chinese.

Problems Reflected by the Changes of Semantics. Character is the record tool and carrier of culture. The changes of the meaning of the character can often reflect the changes of value pursuit in social culture. The changes of the meaning of the character “贵” not only reflect the improvement of the social culture but also reflect some social problems.

In ancient times, to a certain extent the meaning of the character “贵” is related to officials and gentry and correspondent with civilian which has some class consciousness. After the founding of new China, to a certain extent the “贵”-centered culture of wealth and rank was discouraged because of the promotion of concept of equality. On the one hand, this measure make the concept of equality be deeply rooted among the people, on the other hand, it also bring a problem that some excellent inheritances in the culture of wealth and rank are interrupted because of the losing of the meanings of the character “贵” which refer to the value pursuits that caused the misunderstanding of people for the character “贵” in the culture of wealth and rank. 
The character “贵” can best express the ideals and value pursuits of the ancient sages when it is used as a verb. It is proposed by Lao-tzu that "Do not pursue the things with the huge of cost of large numbers of human and financial resources”. The term “不贵” reflects the attention paid to credit. Some terms such as “贵德” and “贵义” can embody the idea of moral and profit and the adoration of the noble moral and character of people in ancient times. In the eyes of people in ancient times, it is a failure that there is no attention paid to the development of moral and character.

The character “贵” embodies the attention paid to social responsibility by people of ancient times when its meaning is hard core as a noun. It is real “贵” to defend the country.

Thus it can be seen the meanings of the character “贵” far beyond the officials, exploitation and class in the eyes of modern people. The partial meanings lost of the meanings of the character “贵” in modern Chinese represent some noble pursuits of the Chinese traditional culture which is very necessary to be rediscovered. At present, it has been recognized by the whole society that excellent traditional culture has very important role in transforming the cohesiveness of of Chinese people and developing our national ideological morality. We also should timely restore the original visage of the culture of wealth and rank and develop the educational value of the character “贵” in the culture of wealth and rank in order to promote the rise of Chinese civilization.

\section{Development of Educational Value}

Educational Significance of the Character “贵”. The educational value of the character “贵” is mainly embodied in three aspects. Firstly, the propositions of advocating morality and advocating justice can educate people about committing promise, paying attention to moral and integrity and that forgetting honour at the prospect of profits is wrong. Mo-tse says that "Justice is more valuable than every thing". Justice is the highest pursuit of ancient sages as the moral principle for evaluating the thoughts and behaviors of people. So Confucius says that "In my eyes, the wealth and rank got with disloyal means is like the floating cloud in the sky". Cao Cao says that "Resigning the rank of nobility and salary, because the reputation should not be damaged by struggling for the fame and wealth, and the morality should not be damaged by pursuing high rank, and that can only be righ". Secondly, the proposition of advocating politeness (regarding the politeness as rank which is also the rank in the eyes of ancient people) can instructs the rich concerning the way to wealth. In the eyes of Confucius, wealth without cockiness is not good as wealth with politeness. In other words, the people firstly become rich should not be arrogant, they should have the social responsibility of advocating politeness. Thirdly, the meaning of hard core of the character "贵” and the evaluation of ancient people of the character “贵” can educate the officials about that only the identity of official is not real rank, working selflessly for the public interest and governing and benefiting the people is the real rank. Zhuang $\mathrm{Zi}$ once said that "The emperor created by the situation of the times is not always to be rank, and an ordinary person is not always to be humble. The difference of rank and humbleness is same with the difference of evildoing and benefactions". This deliberation provides the best annotation for the differences of official and rank. The purpose of being an official is seeking great rank, ie. Better providing service for more people. Cultivating moral character, governing family, administering a country and preserving peace in "Daxue, Liji" can educate the officials to cultivate their own moral character, governing their own family and have a fierce ambition and ideals.

Development Approach of Educational Significance. The first step is carrying forward the essence of Chinese culture and discarding the dross of Chinese culture if we want to develop the educational value of rank. Then we should tell the stories about rank to all the people. For example, people can know from the story "Zeng Zi kill the pig" that it is very important to keep good faith. Lastly, the development of the educational value should depend on integrating the pursuits of "rank" into the live culture closely related to people with the help of various means of popularization. For example, the online reading culture of mobile phone young people like can be the main land of popularization. The story told can be directly provided for the educational objects 
by network platform of mobile phone. As another example, the alley culture (the alley culture itself has many stories about rank) in the city is closely related to the sweet memories of life of people. With "rank" as the topic, arranging and integrating the alley culture can give the public a better impression of the valley. Similarly, the topic culture of park also has many sayings, sentences and stories related to "rank".

\section{Conclusion}

Ancient work people invented and created the character “贵” and gave it many meanings. The meanings without value pursuits of these meanings are still used in modern times. The meanings with value pursuits were once misunderstood and abandoned by the people. Indeed, the pursuits with the insularity of times should be abandoned, for example, the class consciousness embodied in the terms such as “贵戚” and “贵族” should be abandoned. But more value pursuits embody the adoration of benevolence, justice, politeness, wisdom and credit which should be referenced and even studied in modern society. In the eyes of ancient people, there is no "rank" when ceremony disintegration is failure. The good propositions of "rank" ancient people, the noble things of carrying out these propositions of ancient people and the representative figures who proposed and fulfilled these propositions are the three elements of the culture of wealth and rank as an excellent traditional culture.

Civilization construction of modern society should not be water without a source and duckweed without root, it should draw the nourishment and absorb the essence from the fine traditional culture regarded as the soil. So that our modern civilization will become more vital and dynamic.

\section{Acknowledgements}

Fund Project. This article is one of the phases fruits of "Research on the Effect of the Recognition of the Culture of Wealth and Rank in Strengthening the Penetrability of the Core Values of Chinese Socialism" which is a general project of the planned projects of the 13th five-year plan of social sciences (2016) in Jiangxi province (Project Number: 16DQ26).

\section{References}

[1] Ruzhen Jiang, Historical Interpretation and Modern Values of Chinese Traditional Culture[M]. Shangxi, Shanxi Education Press, 1997.

[2] Yande Jia, Chinese Semantics[M]. Peking, Peking University Press, 1992.

[3] Zhonghua Li, Wending Zhang. Discussion on Chinese Traditional Culture[M]. Peking, Joint Publishing, 1988.

[4]Xichen Lv. Chinese Modern Cultural Philosophy[M]. Tianjin, Tianjin Peoples Publishing House, 1993.

[5] Chunming Liu. Confucius's Viewpoint of Wealth and Rank[J]. Journal of Shihezi University (Philosophy and Social Sciences), April, 2004.

[6] Xianyu Ma. Discuss on the Relationship and Meaning of Traditional Culture and Modern Life[J]. Journal of Mudanjiang University, August, 2009. 